\section{POST-EXPOSURE PROPHYLAXIS FOR NON-OCCUPATIONAL EXPOSURETO HIV: EXPERIENCE IN NSW ONE YEAR AFTER THE INTRODUCTION OF THE GUIDELINES}

\section{Patricia Correll, Don Smith and Andrew Grulich}

National Centre in HIV Epidemiology and Clinical Research, University of New South Wales

In December 1998, the NSW Department of Health released guidelines for the use of post-exposure prophylaxis (PEP) in situations of non-occupational exposure to HIV. ${ }^{1}$ This report summarises the first year's results of the study that was instituted as part of these guidelines to monitor the use of PEP.

\section{BACKGROUND}

Only a few health jurisdictions in the world have published policies recommending PEP in the context of non-occupational exposures, although it is recognised that PEP is used informally in nonoccupational settings in a number of countries. The NSW Department of Health is currently the only health jurisdiction in Australia to provide guidelines recommending PEP for nonoccupational exposures to HIV (see Box for a description of the stages of HIV reproduction). Some other states and territories have guidelines in development.

Although there is no direct evidence from randomised controlled trials of the efficacy of PEP for HIV, other data suggest that PEP may be effective. ${ }^{2} \mathrm{~A}$ case-controlled study of health care workers reported a 79 per cent reduction in the risk of seroconversion with zidovudine (a nucleoside analogue reverse transcriptase inhibitor) PEP treatment. ${ }^{3}$ (See Table 1 for more detail on types of antiviral drugs and their modes of action). Animal studies also suggest that PEP may successfully prevent HIV infection. ${ }^{4}$ Randomised controlled trials have demonstrated that antiretroviral treatment

continued on page 114

\section{CONTENTS}

113 Post-exposure prophylaxis for non-occupational exposure to HIV: experience in NSW one year after the introduction of the guidelines

118 Sexual Health, AIDS-HIV, Sexually Transmissible Infection Coordinators contact list

119 The epidemiology of respiratory syncytial virus infections in NSW children, 1992-1997

\section{A Capacity Building Web site}

124 A drinking water investigation

127 NSW Health establishes the Centre for Public Health Nutrition

128 EpiReview : meningococcal disease in NSW 1991-1999

131 FactSheet : Ross River virus infection

132 A cluster of locally-acquired Ross River virus infection in outer western Sydney

134 Infectious Diseases: July

134 Trends

134 Updated infectious disease notification forms 
decreases mother-to-child transmission of HIV, ${ }^{5}$ and part of this effect appears to be through post-exposure prophylaxis in the infant. Evidence to support this has come from a recent study, which found that a single dose of nevirapine (a non-nucleoside reverse transcriptase inhibitor) administered intrapartum, followed by a single dose to the newborn infant reduced HIV transmission by almost 50 per cent. ${ }^{6}$

HIV post-exposure prophylaxis has been available for some time for occupational exposures among health care workers in NSW. ${ }^{7}$ However, more than 90 per cent of HIV transmission episodes in Australia occur in nonoccupational settings through sexual activity, and up to five per cent through injecting drug use. ${ }^{8}$ The risks of transmission associated with unprotected intercourse and needle sharing in discordant couples (where one individual is HIV antibody positive and the other is HIV antibody negative) have been estimated to be at least as high as the risks of transmission in occupational exposures. ${ }^{9}$

PEP against HIV infection comprises four weeks of therapy with highly specialised antiretroviral drugs. In the NSW Department of Health guidelines, two nucleoside analogue reverse transcriptase inhibitors are recommended for most situations, with the addition of a protease inhibitor for certain particularly high risk exposures (Table 2 ). The cost of this treatment to the health care system is approximately $\$ 600$ for double- and $\$ 1000$ for triplecombination therapy.

The types of exposures recommended for PEP in the guidelines include percutaneous and mucous membrane exposures, which may occur from sexual and injecting drug use behaviours. In all situations, the possibility that the source is infected with HIV and the nature of the exposure must be weighed up.
For percutaneous exposures, where the source is known to be HIV positive and with a significant blood exposure to high HIV titre, PEP comprising triple-combination therapy (two nucleoside reverse transcriptase inhibitors and a protease inhibitor) is recommended. PEP is also recommended for unprotected receptive or insertive anal or vaginal intercourse, using two nucleoside analogues in most circumstances, with the addition of a protease inhibitor in situations of particularly high risk.

The guidelines suggest that PEP might be considered in other circumstances, such as percutaneous exposures to blood-stained fluid, and significant mucous membrane exposure to blood or blood-stained fluid. It is recommended not to offer PEP for exposures to non blood-stained fluids, exposures to intact skin, or for needle-stick injuries from discarded injecting equipment.

\section{Observational study of non-occupational PEP in NSW}

In view of the limited evidence regarding the efficacy of PEP, the December 1998 guidelines from the NSW Department of Health recommended that the use of this treatment be closely monitored. A study was initiated to monitor implementation of the guidelines, which is coordinated by the National Centre in HIV Epidemiology and Clinical Research (NCHECR) and the National Centre in HIV Social Research. This study has been approved by the research ethics committee at the University of New South Wales as well as by individual NSW Area Health Services. Coordination of the study was possible through an unrestricted grant from GlaxoWellcome.

\section{METHODS}

In NSW, medical practitioners operating outside hospital HIV specialist units may prescribe specialised drugs for the treatment of HIV infection provided they are registered with the HIV Prescribers Project. This project is funded by the NSW Department of Health and

\section{STAGES OF HIV REPRODUCTION}

1. HIV enters a CD4+ cell.

2. HIV is a retrovirus, meaning that its genetic information is stored on single-stranded RNA instead of double-stranded DNA found in most organisms. To replicate, HIV uses an enzyme known as reverse transcriptase to convert its RNA into DNA.

3. HIV DNA enters the nucleus of the CD4+ cell and inserts itself into the cell's DNA. HIV DNA then instructs the cell to make many copies of the original virus.

4. New virus particles are assembled and leave the cell ready to infect other CD4+ cells. 


\section{TABLE 1}

TYPES OF POST-EXPOSURE PROPHYLAXIS ANDTHEIR MODE OF ACTION.

\begin{tabular}{|c|c|}
\hline Class-Drug & Mode of acton \\
\hline $\begin{array}{l}\text { Non-nucleoside reverse transcriptase } \\
\text { inhibitors (NNRTIs) } \\
\text { - Delavirdine } \\
\text { - Efavirenz } \\
\text { - Nevirapine }\end{array}$ & $\begin{array}{l}\text { The newest class of antiretroviral agents, NNRTIs stop HIV production by } \\
\text { binding directly onto reverse transcriptase and preventing the conversion } \\
\text { of RNA to DNA. These drugs are called 'non-nucleoside' inhibitors } \\
\text { because even though they work at the same stage as nucleoside } \\
\text { analogues, they act in a completely different way. }\end{array}$ \\
\hline $\begin{array}{l}\text { Nucleoside analogue reverse } \\
\text { transcriptase inhibitors } \\
\text { - Didanosine (ddl) } \\
\text { - Lamivudine (3TC) } \\
\text { - Stavudine (d4T) } \\
\text { - Zalcitabine (ddC) } \\
\text { - Zidovudine (ZDV or AZT) } \\
\text { - } \text { Abacavir }\end{array}$ & $\begin{array}{l}\text { The first effective class of antiretroviral drugs was the nucleoside } \\
\text { analogues. They act by incorporating themselves into the DNA of the virus, } \\
\text { thereby stopping the building process. The resulting DNA is incomplete } \\
\text { and cannot create a new virus. }\end{array}$ \\
\hline $\begin{array}{l}\text { Protease inhibitors } \\
\text { - Amprenavir } \\
\text { - Indinavir } \\
\text { - Nelfinavir } \\
\text { - Ritonavir } \\
\text { - Saquinavir }\end{array}$ & $\begin{array}{l}\text { Protease inhibitors work at the last stage of the virus reproduction cycle. } \\
\text { They prevent HIV from being successfully assembled and released from } \\
\text { the infected CD4+ cell. }\end{array}$ \\
\hline
\end{tabular}

provides ongoing education for HIV prescribers throughout NSW. It is through this project that data collection forms for the study have been provided to all doctors who are HIV prescribers in NSW. Hospital emergency departments, sexual health clinics and sexual assault clinics have also been provided with enrolment packs in most Area Health Services via the HIV-Sexual Health Coordinators. Patients who consent have been enrolled in the study when they presented for PEP and are followed up for six months using questionnaires to their doctors.

Enrolments to the study commenced in December 1998. The data collected by the doctor includes demographic information (age, sex, postcode), baseline HIV status and details of the exposure involved. The doctor also collects information about the source person from the PEP recipient. Depending on the recipient's knowledge of the source, this could include the source's sex, HIV exposure category, HIV status and treatment with antiretroviral therapy. All individuals who present and are eligible to be prescribed PEP are also eligible to be enrolled on the study, including those who elect not to take PEP. For those who are prescribed PEP, details of the drug treatment used is sought. Follow-up is conducted after four weeks to assess adherence to treatment and side effects, as well as HIV status. Results of all HIV testing are obtained at the final follow-up after six months. Summary statistics of the data collected have been generated.

\section{RESULTS}

During the period December 1998 to February 2000, 88 participants have been enrolled in the study. The monthly number of prescriptions for non-occupational PEP tended to increase over the first year (Figure 1). The exposure leading to presentation for PEP was male homosexual contact in 70 per cent, heterosexual contact in 10 per cent, percutaneous in 17 per cent, and other exposures in three per cent. Over 25 per cent of percutaneous exposures resulted from assaults with a used syringe, a further 25 per cent was due to community acquired needle stick injuries, and the remaining 50 per cent being related to re-use of injecting equipment. The median time between exposure and presentation for PEP was 30 hours (range 1 to 171 ). The majority of PEP prescriptions (73 per cent) have been for triple-combination therapy. Nearly all prescriptions have been for twice-daily dosing regimens. The source person was known to be HIV positive in 47 per cent overall, although among 
homosexual exposures this was slightly higher (53 per cent) and lower among percutaneous exposures (22 per cent).

The majority (72 per cent) of participants adhered to and completed the four week course of treatment. Over 75 per cent experienced side-effects which were mostly reported as mild, although there were five cases where side-effects were the reason for discontinuing treatment. Four week follow-up has been completed for 61 subjects. There have been no HIV seroconversions, and four participants have been lost to follow-up. Six month follow-up has been completed for 28 subjects, with no seroconversions, and a further four who have been lost to follow-up.

\section{DISCUSSION}

The majority of exposures that have resulted in prescription for PEP have fallen within the NSW Department of Health guidelines. The distribution of risk behaviours among participants is broadly similar to that in people with HIV infection in Australia (NCHECR, 1999), with most being related to male homosexual contact. However, there is a higher representation of percutaneous and 'other' exposures in the study which reflects a greater proportion of cases of assault or accidental injury with a used needle. The NSW Department of Health Guidelines do not recommend offering PEP for needle-stick injuries that occur from discarded injecting equipment in the community, as these cases are usually low risk exposures. This is because injecting drug users have a relatively low risk of HIV infection in Australia, and because the exposure is to a small volume of blood.
In addition, even in cases where the source was HIV positive, the blood is likely to have very low viral load related to viral decay outside the human body. ${ }^{10}$

Despite the guidelines recommending that two drugs are sufficient for most exposures, nearly three-quarters of the prescriptions for PEP in the study have been for three antiretroviral drugs.

A limitation of this study is that not all people who have been eligible for inclusion might be enrolled on the study. We confirmed that we had enrolled almost 100 per cent of eligible patients at one large public hospital and one large private practice. At other sites, it was not possible to determine participation rates. However, the study has been actively promoted to all prescribing general practitioners as well as in all Area Health Services in NSW.

The results of this study of the first year of nonoccupational PEP in NSW raises a number of operational issues, which need to be considered in policy formulation and health service delivery. These include the following:

- How can the prescription of PEP for community acquired accidental needle-stick injury be discouraged given that the likelihood of transmission through discarded injecting equipment is very small?

- Why are doctors and patients exhibiting a preference for three over two drugs?

- Given the evidence that the efficacy of PEP declines with increasing time since exposure, can the time between exposure and prescription be further reduced by the implementation of urgent triaging procedures in public and private settings?

- Should the availability of PEP be promoted among individuals at particular risk? For instance, given that approximately half of the sexual exposures in the

\section{TABLE 2}

ANTIRETROVIRAL DRUGS USED FOR HIV POST-EXPOSURE PROPHYLAXIS IN NSW

\begin{tabular}{|lc|}
\hline Antiretroviral combinations & Number of prescriptions \\
\hline zidovudine-lamivudine-nelfinavir & 28 \\
zidovudine-lamivudine & 22 \\
zidovudine-lamivudine-nevirapine & 8 \\
zidovudine-lamivudine-indinavir & 7 \\
stavudine-didanosine-nelfinavir & 6 \\
stavudine-lamivudine-nelfinavir & 5 \\
other combinations & 8 \\
not prescribed PEP & 4 \\
\hline Total & 88 \\
\hline
\end{tabular}




\section{FIGURE 1}

ENROLMENTS TO STUDY OF NON-OCCUPATIONAL PEP IN NEW SOUTH WALES: DECEMBER 1998 TO DECEMBER 1999

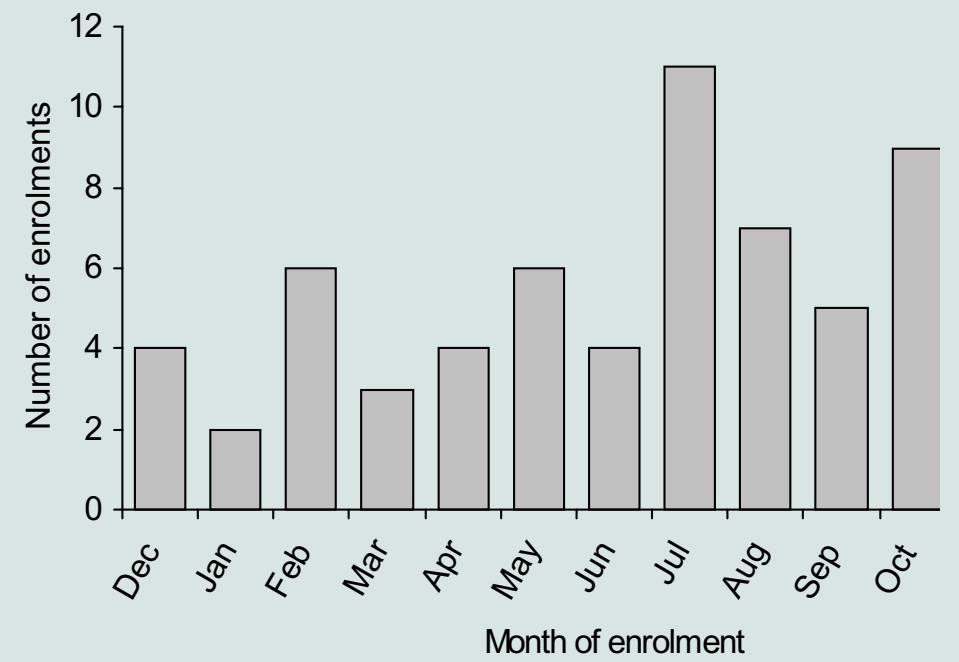

study occurred where the source was known to be HIV positive, should serodiscordant couples be targeted in promoting PEP?

- How can appropriate risk reduction counselling be provided in public and private settings?

Addressing these issues will help ensure the most appropriate and effective use of PEP and assure that PEP is properly positioned as the prevention mechanism of last resort within a broader scheme of HIV prevention.

\section{REFERENCES}

1. NSW Department of Health. Management of non-occupational exposure to blood borne and sexually transmissible diseases. Circular No 97/106. Sydney: NSW Department of Health, 1998.

2. Gerberding J. Prophylaxis for occupational exposure to HIV. Ann Intern Med, 1996; 125: 497-501.

3. Centers for Disease Control. Case control study of HIV seroconversion in health care workers after percutaneous exposure to HIV infected blood-France, United Kingdom and United States, January 1988-August 1994. Morbidity and Mortality Weekly Report 1995; 44: 929-33.

4. Centers for Disease Control. Public Health Service Guidelines for the management of health-care worker exposures to HIV and recommendations for post-exposure prophylaxis. Morbidity and Mortality Weekly Report, 1998; 47: $1-39$.
5. Connor EM, Sperling RS, Gelber R, et al. Reduction of maternal-infant transmission of human immunodeficiency virus type 1 with zidovudine treatment. N Engl J Med 1994; 331: 1173-1180.

6. Guay LA, Musoke P, Fleming T, et al. Intrapartum and neonatal single-dose nevirapine compared with zidovudine for prevention of mother-to-child transmission of HIV-1 in Kampala, Uganda: HIVNET 012 randomised trial. Lancet 1999; 354: 795-802.

7. NSW Department of Health. Blood Borne Infectionsmanagement of health care workers potentially exposed to HIV, hepatitis B and hepatitis C: Circular No 97/12. Sydney: NSW Department of Health, 1998.

8. Katz MH \& Gerberding JL. Post-exposure treatment of people exposed to the human immunodeficiency virus through sexual contact or injection drug use. N Engl J Med 1997; 336: 10971100 .

9. National Centre in HIV Epidemiology and Clinical Research. HIV-AIDS, hepatitis $C$, and sexually transmissible infections in Australia: Annual Surveillance Report 1999. Sydney: National Centre in HIV Epidemiology and Clinical Research, 1999.

10. Van Bueren J, Simpson RA, Jacobs P, and Cookson BD. Survival of human immunodeficiency virus in suspension and dried onto surfaces. J Clin Microbiol. 1994;32:571-574. It 